
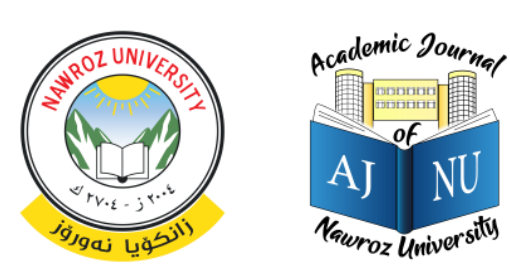

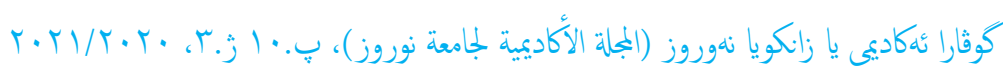

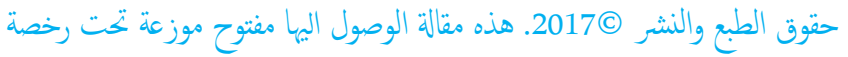
e-ISSN: 2520-789X ،CC BY-NC-ND 4. 0.

https://doi.org/10.25007/ajnu.v10n3a1221

\title{
أثر استخدام استراتيجية التعلم التوليدي على التحصيل المعرفي لمادة الجغرافية لدى طالبات الصف العاشر الادبي
}

ק·م سندس علي حسن، قسم الجغرافية، كلية التربية الإساسية، جامعة دهوك، أقليم كورستان العراق

هدف البحث الحالي اللى التعرف على أثر استخدام استراتيجية التعلم التوليدي على التحصيل المعرفي لمادة الجغرافية لدى طالبات الصف العاشر الادبي، عينة البحث مـن طالبـات الصف العاشر

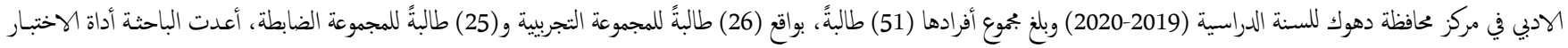

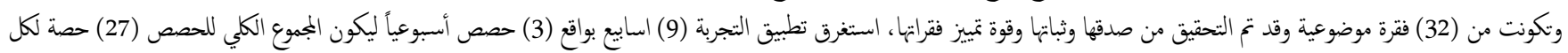

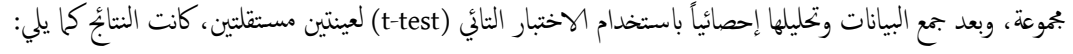
يوجد فرق ذو دلالة احصائية عند مستوى (0.05) بين متوسط درجات تحصيل طالبات الجمموعة التجريبة اللواتي يدرسن مادة الجغرافية على وفق استراتيجية التعلم التوليدي، ومتوسط درجات التحصيل لطالبات المجموعة الضابطة اللواتي يدرسن مادة الجغرافية على وفق الطريقة الكتينيادية في اختبار التحصيل المعرفي لصالح المجموعة التجريبية. الكلمات الدالة: مرض التوحد، الإلتزامات، المدنية، المريض.

1.

" أثر استخدام استراتيجية التعلم التوليدي على التحصيل المعرفي لمادة الجغرافية 1.1

لدى طالبات الصف العاشر الهدبي" ؟

2.1

يمر العالم اليوم بمرحلة من التطور والازدهار التقني والعلمي، الذي أدى الى احداث تغييرات واسعة في طبيعة الحياة المعاصرة في جميع النواحي، والتي كانت سبباً في ظهور مشكلات كثيرة يحتاج حلها الى المزيد من عوامل التطور والتقدم، أن هذه التغيرات قد حدثت كنتيجة مباشرة وغير مباشرة لتقدم العلم الذي أصبح اليوم رمزاً من رموز القوة والذي يسمى بعصر العلم والتكنولوجيا والاتصال. لعل التزاك الهائل والسريع في المعرفة العلمية جعل هذه المرحلة تتزايد وتتضاعف في مدة زمنية قصيرة والتي كأن لها أنعكاساتها على التربية والتعليم عامة وعلى مقررات وطرائت واساليب تدريس العلوم بصورة خاصة، اذا أنه لم يعد في حدود امكأنيات الاساليب التقليدية في التعلم وقدرات المدرس العادية مسايرة العصر ومواكبنه

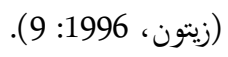

لذلك فأننا لأنستطيع تحقيق ما نهدف اليه من تقدم علمي الا اذاكان لدينا الجبل المؤمن بالعلم والذي يمتلك اتجاهات ايجابية نحو العلم والتقدم العلمي لكي يستطيع مواجهة تحديات العصر والتغيرات السريعة في المجتع، ولتحقيق ذلك اتخذت بعض الدول من التربية كاداة لتحقيق ماتصبوا اليه من اهداف، ولكي تحقيق التربية اهدافها لابد من تربية علمية تعمل على تزويد المتعلم بالمعلومات والمفاهيم
علم الجغرافية من المواد الدراسية المجردة التي تحتاج الى بجد عال من قبل المدرس لإيصال محتوى المعرفة للطلبة مما قد يلاقون صعوبة في فهمها، لأهها تتناج الى تزكيز وأنتباه وملاحظة، اذ اشارت نتائح كثير من الابحاث الى أن طريقة التدريس التقليدية التي تتسم بالالقاء والقيادة والسيطرة المدرس، والتلقي والسلبية والخضوع من جانب الطلبة، فهي لا تسهم في احداث تعلم حقيقي، فقد ترتب على ذلك ارتفاع الاصوات المطالبة بتطوير الندريس وطرائقه التي يثرك الطلبة فيها، وتزيد من ايجابتهم في الموقف التدريسي، ويتحول التعلم من السلبية الى تعلم نشط يكونون فيه مدفوعين الى المعرفة فيا يتعلمون (رشيد، 2015: 2). يعد أنموذج التعلم التوليدي من النماذج الحديثة التي تؤكد على التعلم ذي المعنى وتركز على نشاط المتعلم أثناء عملية التعلم، مما يزيد من قدرته على الربط والفهم بين المعلومات وبقاء عملية التعلم لمدة طويلة. حيث لاحظت الباحثة كثرة القصور في تدريس مادة من خلال استخدام المدرسين الطرائت تدريس تقليدية، وإجراء بعض المقبلات مع المدرسين للوقوف على المشكلات التي تواجمم اثناء التدريس، فضلا عن نتاجُ العديد من البحوث الدراسات السابقة في هذا المجال، وتتحدد مشكلة البحث الحالي في أن طلبة المرحلة الادبية بشكل عام ومنخفضي التحصيل بشكل خاص يوابجون صعوبات في تعلم الجغرافية. وتتلخص مشكلة البحث في التساؤل الرئيس التالي: 


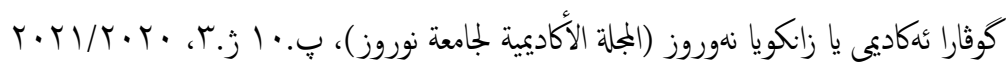

لقد جرت محاولات عديدة استراتيجيات ونماذج تنفيذية يتبعها المدرس في غرفة

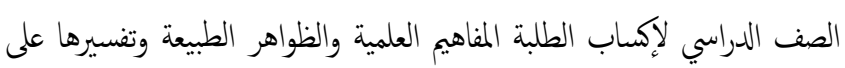
وفق المرتكزات الاساسية للفلسفة البنائية، وتؤكد هذه الاسترتيجيات على لى المشاركة الفكرية العقلية البنائية للطلبة في نشاطات التعلم بحيث يحدث تعلم ذو معنى قائم على الفهم (أمد، 2013: 321-322). من ابرز الناذج استراتيجية التعليم التوليدي في تدريس الجغرافية، والذي يتضمن عمليات توليدية يقوم بها المدرس لربط المعلومات الجديدة بالمعرفة والخبرات السابقة، كما يؤكد على تشخيص وتصويب الخبرات الخاطئة لدى الطلبة اثناء دراسة الجغرافية كما بهتم بتوليد الطلبة للعلاقات ذات المعني بين اجزاء المعلومات

التي يتم تعلمها.

تعود أهمية استراتيجية التعليم التوليدي في تدريس الجغرافية كاحد نماذج النعلم للوصول بالطلبة المى مابعد المعرفة، ونقل الخبرة للاستفادة منها في بناء خبرات مرتبطة بمواقف جديدة من خلال استراتيجيات عديدة تساعد الطلبة على استخدام محاراته التفكيرية ليصبح اكثر قدرة على حل مشكلاته اليومية(ضهير،

(40:2009

في ضوء ماسبق اصبح من الواضح أن الأسس التي انطلق منها استراتيجية التوليدي في تدريس الجغرافية لاتختلف عن الأسس التي يقوم عليها التعلم البنائي

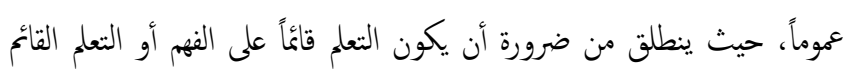
على المعنى، وذلك من خلال تكوين الطلبة للعلاقات بين الخبرات السابقة والنعلم الجديد، وضرورة أن يبنى الطلبة المعرفة بنفسه من خلال عمليات توليدية يستخدها لتعديل الافكار والمعارف الساذجة حول الاحداث والظواهر الى لى

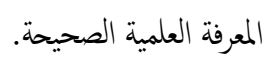
من خلال ماتقدم تتضح أهمية هذا البحث من خلال: العمل على تقليل الصعوبات التي تواجه الطالبات في دراستهن لمادة

$$
\text { الجغرافية والتي تعد من المواد الدراسية المهمة. }
$$

أهمية المراحلة العاشر الادبي كوها مرحلة انتقالية تعد الطالبات الى الانقال

$$
\text { الى التخصص في المرحلة اللاحقة. }
$$

اهمية استراتيجية التعلم التوليدي والذي يعد من الاتجاهات الحديثة في

$$
\text { التدريس والذي يركز على دور الطلبة في العملية التعليمة. }
$$

والنظريات والقوانين وتنمية محاراته واتجاهاته العلمية وطرائق تفكيره التي تجعله

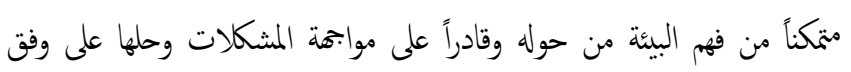
منهج علمي سليم(خضر ، 2006: 17). لقد اهمت التربية الحديثة بايجاد اساليب وطرائق تدريسية كفيلة بايصال المادة العلمية الى اذهان الطلبة معتمدة على المناجج الدراسية بمفهوها الحديث، اذ يعد المنهج اداة التربية الفالة التي من الضروري تحديثها لغرض ربطها بالتطورات المعاصرة (المشهدأني، 1998: 2). يشير الخليلي وآخرون(1995) الى أن واقع المعرفة متغير ، ولذلك فان البحوث العلمية المتصلة بتطوير المناجه على مستوى العالم، أظهرت باننا نجد أنفسنا أمام گ هائل من المعرفة يزداد يوماً بعد يوم ولا سيا في مجال العلوم الطبيعية ومنها الجغرافية، لأن من خصائص العلم الديناميكية أنه لا يقف عند حد معين بل أنه يصبح من الضروري مواكبة التقدم والتطور في مجال المعرفة، وتبعاً للتطو العلمي فأن اهداف تدريس الجغرافية في تغير مستمر، كما أنه مع التطور التقني المتسارع

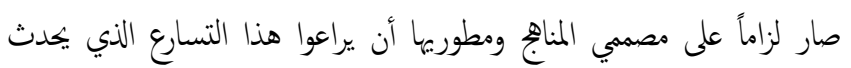
تقدمأ كبيراً في المجال التقني ولا سيا في العقود الاخيرة (الخليلي وآخرون، 1995:

لكي يتحقق التدريس الجيد، ينبغي أن يعرف الطالبة الهدف من دراسته موضوعاً

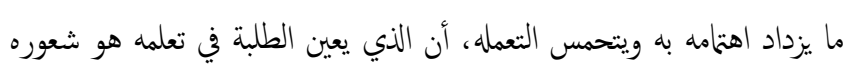
بأن هناك هدفاً وراءكل شيء يتعلمه. أن هذا الشعور القىى على عاتق مدرسي الاجتاعيات عموماً والجغرافية خصوصاً

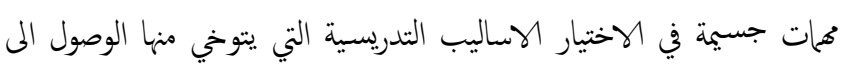
الهدف المراد تحتيق في البرامج التعلمية وأن يعتمد اختياره هذا على مدى مناسبتها لخصائص الطلبة وحاجاتهم وطبيعة المتوى الدراسي والاهداف التعلمية والومكانات المادية والبشرية المتوافرة. أن اساليب التدريس وطرائقه ليست واحدة في كل مجتع بل هي وليدة حاجات وظروف ومطالب اجتاعية معينة، ومن ثم فهي تتغير كلما تغيرت الاهداف النعلمية والاهتمات التزبوية لمواجتة متطلبات الجمتع وحاجاته كما يشملها التعديل كلما تعددت وتنوعت مصادر المعرفة. من اجل تحسين فعالية العملية التعليمة، يككن أن يطور المدرس العديد من الادوات الخختلفة المستخدمة في تحسين التحصيل العلمي. 


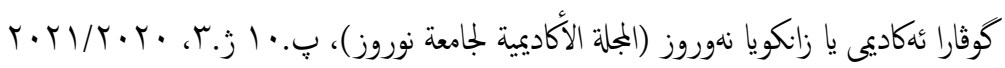

التعلمية المخططة وبلوغ الاهداف التربوية المنشودة " (زاير وآخرون،

(44:2014

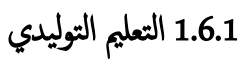

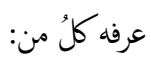

أهمية ماسيتوصل الية البحث من نتاجُُ يككن أن تسهم في رسم معالم جديدة

في اختيار الطرائق المناسبة في تدريس مادة الجغرافية، ومساعدة المدرسين

والقائين على العملية التعليمية للإفادة منها في تطوير تدريس الجغرافية.

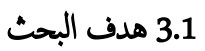

عبد السلام (2006) بأنها: "نموذج لتدريس الفهم وتعلم أنواع العلاقات التي يجب على الطلبة أن يبنوها بين المعرفة الخزونة وتذكر الخبرة والمعلومات

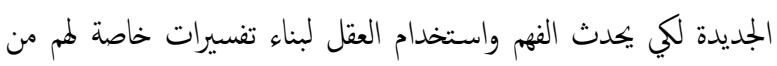
خلال الثفاعلات الإجتاعية بين المتعلمين والمدرس" (عبدالسلام، 2006:

.$(161$

صالح (2009) بأنه: "نموذج وظيفي للندريس هيدف الى اكساب الطالب

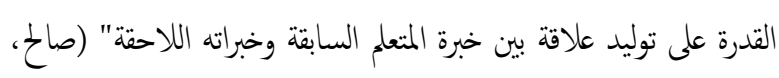

تعرف الباحثة استراتيجية التعلم التوليدي اجرائياً بأنها: بموعة من الخطوات التي تستعملها المدرس الجغرافية في تدريس موضوعات محددة في مادة الجغرافية لطالبات الصف حادي عشر الادبي (الجموعة التجريبة) والتي تكون من اربعة اطوار هي الطور: (التهيدي والتزكيزي والتحدي والتطبيقي).

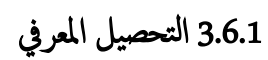

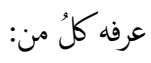

الكبيسي وهادي (2012): "إثبات القدرة على أنجاز ما اكتسب من

الخبرات التعليمة التي وضعت من اجله" (الكبيسي وهادي، 2012: 18). أبو جادو (2013): "مصلة ما يتعلمة الطلبة بعد مرور مدة زمنية، ويكن قياسه بالدرجة التي يحصل عليها الطلبة في اختبار تحصيلي، وذلك لمعرفة مدى نجاح الاستراتيجية التي يضعها لها المدرس ليحقق أهدافه، وما يصل

إليه الطالب من معرفة تترجم إلى درجات" (أبو جادو، 2013: 425). وتعرف الباحثة اجرائياً: هو مجموعة المعلومات التي تحصيل المعرفي عليها الطالبة بعد دراستها مادة الجغرافية للمرحة العاشر الادبي، وتقاس بالدرجة الكلية التي تحصل عليها في الاختبار الذي أعدته الباحثة لهذا الغرض.
مهدف البحث الحالي الكشف عن "أثر استخدام استراتيجية التعلم التوليدي على التحصيل المعرفي لمادة الجغرافية لدى طالبات الصف العاشر الادبي".

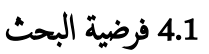
على وفق هدف البحث يكن صياغة الفرضية الصفرية الاتية: "لا يوجد فرق ذو دلالة احصائية عند مستوى (0.05) بين متوسط درجات تحصيل طالبات المجموعة التجريبة اللواتي يدرسن مادة الجغرافية على وفق استراتيجية التعلم التوليدي، ومتوسط درجات التحصيل لطالبات الجموعة الضابطة اللواتي يدرسن مادة الجغرافية على وفق الطريقة الهنتيادية".

5.1

يككن تحديد البحث الحالي بما ياتي:

طالبات الصف العاثر في المدارس الادبية الصباحية في مدينة دهوك

للسنة الدراسية (2019-2020).

منهج الجغرافية المقرر تدريسه من قبل المديرية العامة للمناجه في وزارة التربية في اقليم كوردستان العراق لطلبة الصف العاشر الادبي للسنة الدراسية

(2020-2019)

الكورس الدراسي الاول للسنة الدراسية (2019-2020).

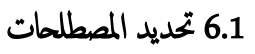

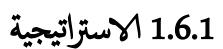

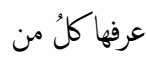

بودي والحزاعلة (2012) بأنها: "خطة من اجل تحقيق الاهداف التعليمية فهي تضع الطرق والتقنيات او الإجراءات التي من المؤكد أن المتعلم يفعلها في الواقع ليصل للهدف" (بودي والخزاعلة، 2012: 17). زاير وآخرون (2014) بأهها: "جموعة الإجراءات والوسائل التي تستعمل من المدرس ويؤدي استعالها الى تمكين الطلبة من الافادة من الحبرات 


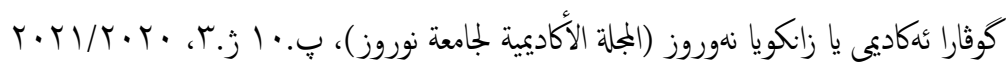

3.1.2 مراحل استراتيجية التعلم التوليدي

تتم عملية الندريس وفقاً استراتيجية التعلم التوليدي باربعة المراحل وهي كالاتي:

المرحلة الأولى (الطور التهيدي): يمهد المدرس للدرس من خلال المناقشة

الحوارية واثارة اسئلة يستجيب لها الطلاب بالاجابة اللفظية او الكنابة في

دفانره اليومية فاللغة بين المدرس والطلاب تصبح اداة نفسية للتفكير

والتحدث وفي هذه المرحلة تتضح المفاهيم اليومية لدى الطلبة من خلال اللغة والكنابة والعمل ومحورها التفكير الفردي للطلبة تجاه المفهوم.

المرحلة الثأنية (الطور التركيزي-البؤرة): يوجه المدرس الطلبة للعمل في

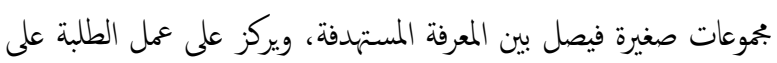
المفاهيم المستهدفة مع تقديم المصطلحات العلمية واتاحة الفرصة للمفاوضة

$$
\text { والحوار بين المجموعات. }
$$

المرحلة الثالثة (الطور المتعارض-التحدي): هذا الطور يقود المدرس مناقشة الطلاب جميعهم مع اتاحة الفرصة للطلبة بالمنافسة بملاحظاتهم وفهمهم ورؤية أنشطنه ومساعدتهم دعائم التعلمية المناسبة، واعادة تقديم المصطلحات العلمية، والتحدي بين ما كان يعرفه الطلبة في الطور التمهيدي وما عرفه

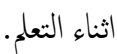
المرحلة الرابعة (الطور التطبيق): يستخدم الطلبة المعرفة العلمية كأدوات وظيفية لحل المشكلات وايجاد نتائج وتطبيقات في مواقف حيانية جديدة كما تساعد على توسع نطاق المعرفة التي تعلمها (النجدي وآخرون، 2005:

\subsection{2 عناصر استراتيجية الثعلم التوليدي}

الاستدعاء: يتضمن سحب المعلومات من الذاكرة طوية المدى للطلبة والهدف من الاستدعاء أن يتعلم الطلبة معلومات تستند على الحقيقة، ويتضمن تقنيات مثل التكرار، الممارسة، المراجعة، واساليب تقوية الذاكةة. النكامل: يتضمن مكاملة الطلبة للمعرفة الجديدة بالعلم مسيق، وهدفه تحويل المعلومات الى شكل يسهل تذكره، ومن طرق النكمل(اعادة صياغة خلاصة في صيغة قصصية، التخليص أي يعيد رواية المحتوى وشرحة بدقة، توليد الاسئلة وتوليد المناظرات).

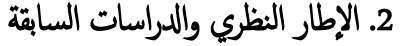

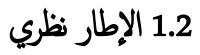

1.1.2 استراتيجية التعلم التوليدي

التعلم التوليدي هو العملية النشطة وأنه عملية بناء الربط أو الصلة بين المعرفة الجديدة والقديمة، وجوهر استراتيجية التعلم التوليدي يكون العقل ولايكون مستهاك سلبي للمعلومات (عبد السلام، 2006: 151). يلخص (White\&Guston, 1989: 89) و (Wittrock, 1991: 85) الأسس التي ارتكز عليها استراتيجية التعلم التوليدي في تدريس الجغرافية بالآتي: ينى الطلبة المعنى عن طريق تكوين علاقات بين المفاهيم الجديدة والمفاهيم السابقة، ولايقتصر تدريس الجغرافية على الطرائق المعتادة التي تغطي موضوعات المنهج عرضها فقط لوجتات نظر العلماء الظواهر العلمية، بل يبداً تدريس الجغرافية مع نمو وتطور مفاهيم اثناء تعلم الجغرافية من خلال قيام الطلبة بتوليد المعاني لتغيير المفاهيم البديلة لديه

يستخدم الطلبة العمليات التفكيرية لفهم ومعرفة الجغرافية بعني أن يكون الطلبة نشطا ليكون العلاقات بين اجزاء المعرفة التي يتم تعلمها، وتوليد المعني بين معرفة الطلبة وخبراته السابقة. لابد وأن يتعدى تعلم الطلبة حدود التعلم الى ما فوق التعلم، أو ما بعد التعلم كما ينبني أن يعبر حدود المعرفة المى مافوق المعرفة، أو ما بعد المعرفة وهذا يعني أستمرارية التعلم لتحقيق مزيد من التعلم (حميد وسبجى، 2019:

2.1.2 أهداف استراتيجية الثعلم التوليدي

تنشيط جانبي الدماغ من خلال إيجاد علاقات منطقية ومتشعبة حول التصورات البديلة من اجل البناء المعرفي في بنية الدماغ تزيد من قدرة

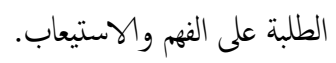
تعمل على تنمية التفكير فوق المعرفي وهو نناج توالد الافكار عند الطلبة. أن إحداث تغير مفاهيمي في بنية الدماغ يزيد الطلبة من وضوح الافكار والهياكل المعرفية الحياتية بصورة افضل (عأنة والجيش، 2008: 239- 
ميسر ومنظم ومرشد لعملية التعلم والتعليم (إساعيل، 2011: 240).

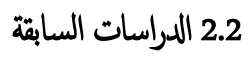

اطلعت الباحثة على عدد من الدراسات السابقة ذات صلة لمتغير البحث المستقلة

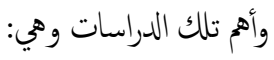

1.2.2 دراسة أحمد (2009)

هدف من هذه الدراسة هو التعرف على أثر استخدام نموذج التعلم التوليدي في تدريس الجغرافية على التحصيل المعرفي وتنمية الوعي بالكوارث الطبيعية لدي طالبات الصف الأول الثانوي، واستخدام الباحث المنجج التجريب التبوي ذي المجموعتين المتكائتين، وطبقت الدراسة على عينة الدراسة من(62) طالبة من طالبات الصف الأول الثانوي، وقام الباحث ببناء أدوات الدراسة تمثلت في اختبار في التحصيل المعرفي، ومقياس الوعي بالكوارث الطبيعية، وتمت معالجة البيأنات إحصائياً باستعال اختبار (t-test) لعينتين مستقلنين ومعادلة الفا كرونباخ، معادلة كودر يتشاردسون(20) و(21) وتحليل التباين الاحادي، وكأنت أبرز النتائج، وجود فرق بين متوسطي درجات طالبات المجموعة التجريبية وطالبات المجموعة الضابطة في التطبيق البعدي للاختبار التحصيلي لصالح طالبات المجموعة النجريبية، ووجود فرق بين متوسطي درجات طالبات المجموعة النجريبية والضابطة في التطبيق البعدي لمقياس الوعي بالكوارث الطبيعية لصالح طالبات

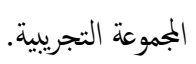

2.2.2 دراسة الكبيسي (2012)

هدف من هذه الدراسة هو التعرف على اثركل من استراتيجتي التعلم التوليدي

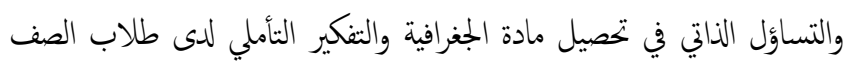
الخامس الادبي، وطبقت الدراسة على عينة الدراسة من(60) طالبا تم توزيعهم الى ثلاث بمموعات، مجموعة تجريبة اولى تكونت من (20) طالباً درسوا باستراتيجية التساؤل الناتي، ومجموعة تجريبية ثانية تكونت من (20) طالباً درسوا باستراتيجية النعلم التوليدي، ومجموعة تجريبية ثالثة تكونت من (20) طالبا درسوا باستراتيجية التعلم التوليدي، وأعد اختبار مهارات التفكير التأملي الذي تكون من (40) فقرة من نوع الاختيار من متعدد موزع على مهارات النفكير التأملي، وتمت معالجة البيأنات إحصائياً باستعال اختبار (t-test) لعينتين مستقلتين، وتوصلت الدراسة الى عدة النتاجُ ابرزها يوجد فرق ذو دلالة احصائية بين متوسطي
التنظيم: عملية ربط الطلبة بين العلم المسبق والافكار الجديد في طرق ذات معني مغزى ويتضمن تقنيات مثل تحليل الافكلر الرئيسة، التلخيص، التصنيف، التجميع وخرائط المفاهيم. الاسهاب: عملية اتصال المادة الجديدة بالمعلومات او الافكرر في عقل الطلبة، وهيدف فضلاً عن الافكار الى المعلومات الجديدة، ومن طرقه (توليد الصور العقلة والاسهاب في جمل مفيدة)(الدواهيدي، 2007:

5.1.2 عمليات استراتيجية التعلم التوليدي

تصورات المعرفة والخبرة: الكشف عن تصورات الطلبة وخبرتم السابقة الى موضوع معين، وتصحيح تصوراتهم الى الموضوع من خلال توجيه الاسئلة

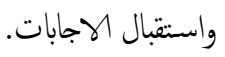

الافعية: يعمل المدرس على تحفيز الطلبة للتعلم من خلال الأنشطة الصفية التي تخفز وتعزز الثقة لديهم واكتساهم الفهم العميق حول خبرات الحياة اليومية. الأنتباه: يوجه المدرس طلبة من خلال توجيه الاسئلة وشرح وتفسير المعنى الذي تم التوصل اليه واحداث توليد في بنية المعلومات وعلى المشكلات المرتبطة بالمفهوم وما عندهم من خبرات سابقة. التوالد: يترك المدرس الطلبة لكي يولدوا المعنى وهذا يؤدي الى بهد هو ابعد من خلال مخططات المفاهيم والرسوم والاشكال وغيرها، والاستعأنة بالأمثلة واللامثلة في توليد العلاقات بين المفاهيم او التشاهات وغيرها. ما وراء المعرفة: استخدام استراتيجيات تعليم لمساعدة الطلبة على استحدام عملياتهم الدماغية لفهم وتطبيق واستخدام المعلومات التي تم تعلمها، وفيها يقدم اسئلة ومنها (تنبا، لاحظ، فسر،....) 6.1.2 دور المدرس في استراتيجية الثعلم التوليدي يطرح الاسئلة للكشف عن التصورات البديلة عند الطلبة. يقدم مفاهيم تتعارض مع خبرات الطلبة لتصحيح مفاهيهم. يستعين باستراتيجيات لأحداث تغير مفاهيم واحداث توالدات فكرية تمكن الطلبة من فهم المفاهيم ووضوح الافكار. 


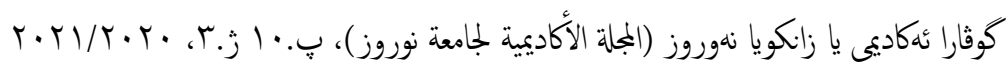

اما البحث الحالي سيهدف تعرف أثز استخدام استراتيجية النعلم التوليدي على التحصيل المعرفي لمادة الجغرافية لدى طالبات الصف العاشر الادبي.

2.3.2

تباينت عينة الدراسات السابقة من حيث عدد افرادها والجنس والمرحلة الدراسية

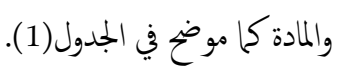

جدول(1) عينات الدراسات السابقة من حيث عدد افرادها والجنس والمرحة الدراسية المادة

\begin{tabular}{|c|c|c|c|c|}
\hline المادة & المرحلة الدراسية & 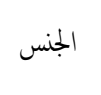 & عدد افراد & اسم الدراسة والسنة \\
\hline الجغرافية & الأول الثانوي & الطالبات & 62 & أحمد (2009) \\
\hline الجغرافية & الصف الخامس & طلاب & 60 & الكبيسي(2012) \\
\hline التاريخ & الخامس الابتدائي & تلميذا & 53 & الطلاع(2013) \\
\hline
\end{tabular}

أ. اختلفت الدراسات السابقة من حيث عدد افراد العينة فقد تراوح عدد

افراد العينة بين(62) و(53) طالباً وطالبةً، اما البحث الحالي فقد بلغ عدد

$$
\text { افراد عينته من (51) طالبةً من طالبات الصف العاثر الادبي. }
$$

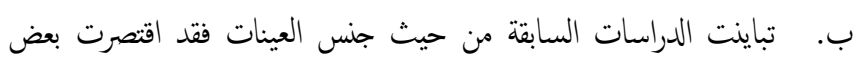
الدراسات على الطلاب فقط او الطالبات فقط او الطلبة من كلا

الجنسين، اما عينة البحث الحلالي فقد اقتصرت على الطالبات فقط.

ت. اما المرحلة الدراسية فقد تباينت الدراسات السابقة في ذلك مابين الابندائي والمتوسط والخامس الادبي، اما البحث الحالي فقد طبق تجربته

$$
\text { في المرحلة العاشر الادبي. }
$$

ث. أن المادة الدراسية للدراسات السابقة جميعها ضمن تخصص التاريخ والجغرافية كذلك البحث الحالي فهو ضمن تخصص الجغرافية.

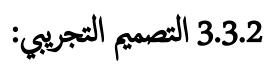

اعتمدت الدراسات السابقة المنجج النجريبي والتصاميم النجريبية ذات الجمموعات المتكفئة حيث اغلها استعملت التصميم التجريبي ذي المجموعتين الوول تجريبية والثانية ضابطة، اما دراسة الكبيسي (2012) اعتمدت على ثلاثة بمموعات تجريبة، اما البحث الحالي فقد اعتمد على مجموعتين الوول تجريبية والثانية ضابطة.

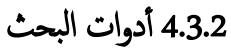

تبأنيت الدراسات السابقة في استخدام أدوات البحث من حيث نوعها وعدد فقراتها، حيث اعتمدت اغلب الدراسات على اختبار التحصيل المعرفي عدا دراسة
درجات مجموعات البحث في تنمية همارات التفكير التأملي لدى الطلاب والطالبات

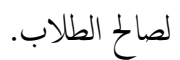

3.2.2 - 3 دراسة الطلاع (2013)

هدف من هذه الدراسة هو التعرف على أثر استعال نموذج التعلم التوليدي في تحصيل تلاميذ الصف الخامس الابتدائي في مادة التاريخ وتمنية المهارات الإجتاعية لاسهم، استخدم الباحث المنهج التجربي، واعتمد على التصميم التجربي ذي الجمموعتين المتكافئين، الاولى تجريبية والأخرى ضابطة، وشملت عينة البحث (53) تلميذاً، وقد وقع الاختيار عليها قصدياً، قسمت العينة بطريقة عشوائية على بمحوعتين متكافئتين، الأولى تجريبية ضمت (27) تلميذاً درس أفرادها على وفق نموذج التعلم التوليدي، والثانية ضابطة ضمت (26) تلميذاً درس أفرادها على وفق الطريقة الاعتيادية، ومقياس للمهارات الإجتاعية قد تبنى الباحث مقياس البدري (2009) بعد التحقيق باستعال الاختبار التائي (t-test) لعينين مستقلتين وتحليل التباين الحادي، ومعامل صعوبة الفقرة، ومعادلة التمييز، وبعد إجراء التجرية الأساسية أظهرت النتائج ابرزها وجود فروق دالة إحصائيًا في علاج التصورات البدية لصالح المجموعة التجريبة التي درست وفق استراتيجية التعلم التوليدي.

3.2 مؤشرات ودلالات من الدراسات السابقة: بعد استعراض الدراسات السابقة استخلصت الباحثة مجوعة من المؤشرات والدلالات واجريت مناقشة لتلك الدراسات لبيأن نقاط التشابة والاختلاف بنيها فضلا عن اجراء موازنة مع البحث الحالي في الاجراءات والنتائُ التي توصلت الهيا

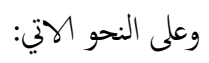

1.3.2 تباينت الدراسات السابقة من حيث اهدافها فني دراسة أحمد (2009) هدفت الى النعرف على أثر استخدام نموذج التعلم التوليدي في تدريس الجغرافية على التحصيل المعرفي وتنمية الوعي بالكوارث الطبيعية لدي طالبات الصف الأول الثانوي، ودراسة الكبيسي (2012) هدفت الى تعرف اثر كل من استراتيجتي التعلم التوليدي والتساؤل الذاتي في تحصيل مادة الجغرافية والتفكير التأملي لدى طلاب الصف الخامس الادي،، اما دراسة الطلاع (2013) هدفت الى تعرف أثر استعمال نموذج التعلم التوليدي في تحصيل تلاميذ الصف الخامس الابتدائي في مادة التاريخ وتنمية المهارات الإجتماعية لديهم، 


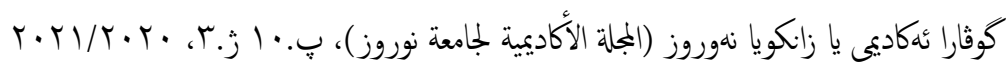

ب. ب.عينة البحث: تم اختيار مدرستين(الدراسة الصباحية) وهي كل من اعدادية (نئمةد) للبنات لنكون المجموعة التجريبية واعدادية (هةسار) للبنات لنكون المجموعة الضابطة بشكل قصدي وذلك لنعاون ادارة المدرسة ومكان المدرستين في منطقتين متساويتين من الناحية الإجتاعية والاقتصادية فضلا عن قرب المدرستين من مكان سكن الباحثة، وبعد اختار الباحثة شعبة من كل مدرسة لتمثل إحداها المجموعة التجريبية، والأخرى الجمموعة الضابطة وبصورة عشوائية، إذ بلغ عدد أفراد مجموعتي البحث (51) طالبةً بواقع (26) طالبةً للمجموعة النجريبية و(25) طالبةً للمجموعة الضابطة، ارتأت الباحثة استبعاد الطالبات الراسبات وذلك امتلاكهن خبرة سابقة عن المادة إحصائياً فقط. وكما مبين في الجدول (2). جدول (2) عينة الطالبات وتوزيعهن الى يموعتي البحث

\begin{tabular}{|c|c|c|c|c|c|}
\hline عددالطالبات & عددالطالبات & قددالطالبات & المدرسة & المجموعة & الشعبة \\
\hline 26 & 4 & 30 & نأمهد ئامادهيا & التجريبية & $i$ \\
\hline 25 & 4 & 29 & ئامادهيا هلسار & الضابطة & ب \\
\hline 51 & 8 & 59 & & المجموع & \\
\hline
\end{tabular}

من اجل الحصول على بموعتين متكافئتأن في عدد من المتغيرات كافات الباحثة بين بموعتي البحث بالمتغيرات الاتية الجدول (3) يوضح ذلك بك بك

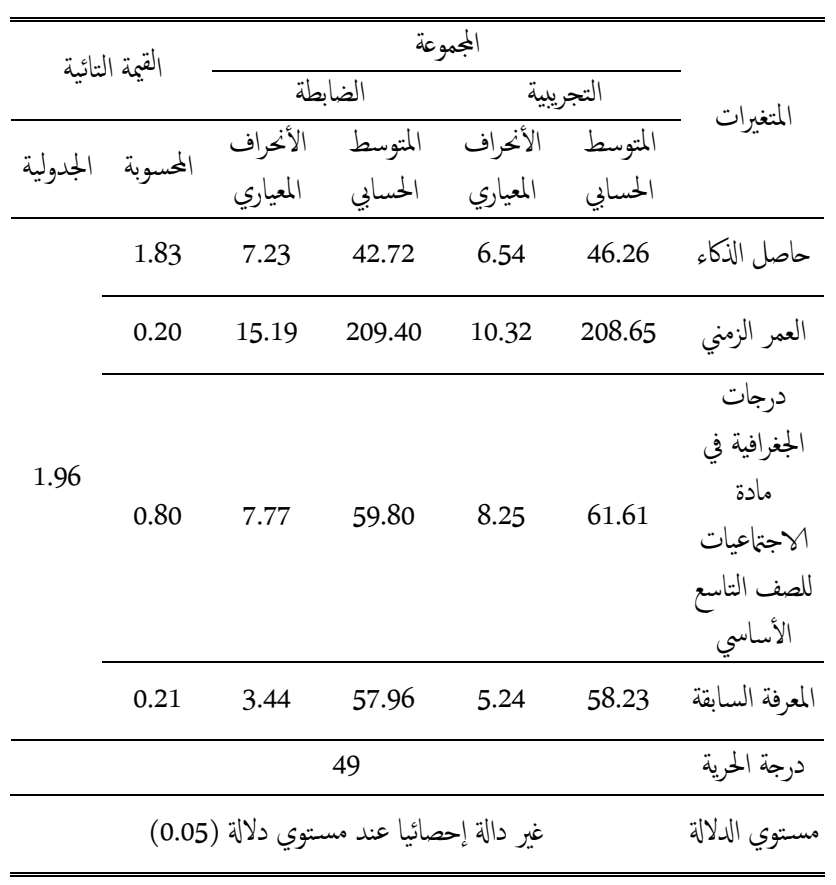

أحمد (2009)، اختبار الوعي بالكوارث الطبيعية، اختبار التفكير التأملي، اختبار لقياس المهارات الإجتاعية، اما البحث الحالي اعتمد اختبار التحصيلي المعرفي لمادة

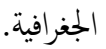

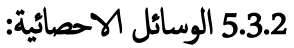

تنوعت الوسائل الاحصائية فقد استخدمت الدراسات الوسائل الاتية: الاختبار التائي لعينتين مستقلتين (t-test)، معامل ارتباط بيرسون، معادلة الفا كرونباخ، معادلة كودر يتشاردسون(20) و(21) وتحليل التباين الاحادي، ومعامل صعوبة الفقرة، ومعادلة التميز. اما البحث الحالي سيستخدم معامل ارتباط بيرسون، والاختبار التائي (t-test) لعينتين مستقلتين، ومعادلة الصعوبة والتمييز.

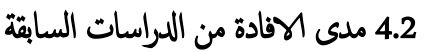

بعد استعراض الدراسات السابقة استفاد الباحثة منها في جوانب عدة هي: (بلورة مشكة البحث وتحديد ابعادها ومجالاتها، وتحديد الادوات التي ستستعمل في هذا البحث، وتحديد عدد افراد العينة والمتغيرات التابعة، وما لاحظنهُ الباحثة من خلال دراسات المحور الثاني أن استعمال اساليب وطرائق تدريس، واختيار الوسائل الاحصائية المناسبة التحليل البيانات وتفسير النتأُج، وموازنة نتاجُج

$$
\text { البحث الحالي مع نتائُ الدراسات السابقة. }
$$

5.2 منهجية البحث وإجراءاته

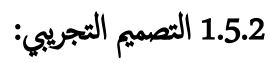

لتحقيق هدفا البحث اعُمتد التصميم التجريبي إذ يتضمن هذا التصميم بمحوعتين متكائتين في عدد من المتغيرات، وكما موضح في الشكل (1) وكالأتي:

\begin{tabular}{|c|c|c|c|}
\hline اختبار بعدي & المتغير التابع & المتغير المستقل & الجموعة \\
\hline \multirow{2}{*}{ المتحصيل } & \multirow{2}{*}{ التحصيل } & استراتيجية التعلم التوليدي & التجربية \\
\hline & & الطريقة الاعتيادية (التقليدية) & الضابطة \\
\hline
\end{tabular}
أ. بجتع البحث: تحديد مجتمع البحث من جميع طالبات الصف العاشر الادبي في المدارس الصباحية الادبية في مدينة دهوك للسنة الدراسية (2019-

2020) والبالغ عددهن (2685) طالبة موزعات الى (12) اعدادية(1).

1المديرية العامة لتربية محافظة دهوك، إحصائية قسم التخطيط التزبوي للسنة

(2020-2019) 


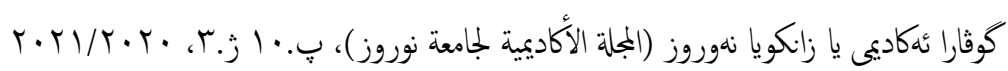

ب. صدق أداة اختبار التحصيل المعرفي: للتحقيق من صدق الاختبار اعتمت الباحثة الصدق الظاهري وعرضتها الأداة بصيتها الولية الى بموعة من ذوي الخبرة والاختصاص في مجال القياس والثقويم وطرائق الندريس،

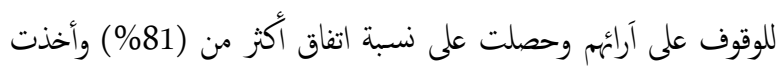
الباحثة باَراء المحكين في اجراء التعديلات على البعض منها وإعادة صياغة

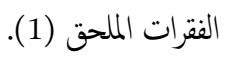

ج· معامل صعوبة الفقرات: استخدمت الباحثة معادلة مستوى الصعوبة للفقرة وتبين أن مستوى صعوبة الفقرات ترواح بين (0.22 - 0.76 ) لجميع فقرات الاختبار، ويرى بلوم وآخرون أن الفقرة الاختبارية تعد مقبولة إذا كانت صعبتها تترواح بين (0.20 - 0.80) (Bloom et. al, 1971: 66 وهذا يعني أن جميع فقرات الاختبار تعد مقبولة من حيث مستوى صعوبها. قوة تميز الفقرات: حللت الباحثة إحصائياً فقرات الاختبار لاستخراج معاملات القوة التميزية لها وللحكي على مدى صلاحيتها إحصائيًا باستخدام معادلة تمييز الفقرة تراوحت القوة التمييزية بين (0.30 0.59) لجميع فقرات الاختبار، وأن الفقرات نكون ميزة إذا كانت قوة تمييزها أعلى من (0.25).(الزوبعي وآخرون، 1981: 8) وهذا يعني أن جميع فقرات الاختبار تعد مقبولة من حيث مستوى تميزها. فعالية البدائل الخاطئة: حسبت الباحثة فعالية البدائل الخطأ لكل فقرة من فقرات الاختبار في النصف السفلي فوجدت أن عدد الطالبات اللواتي اخترن كل بديل من البدائل الخاطئة في كل فقرة من فقرات الاختبار كان اكثر من عدد اقرانهن في النصف العلوي وأن نسبة الفرق كان اكثر من (5\%) وهذا يعني آن كل بديل من البدائل الخاطئة في كل الفقرات كانت جيدا وجذاباً.

ثبات اختبار التحصيل المعرفي: هناك عدة طرائق لقياس الثبات واعتمد الباحثة على طريقة اعادة الاختبار للتحقيق من ثبات الأداة إذ أعادت تطبيقها على (80) طالبةً من العينة نفسها بعد (14) يوماً من التطبيق الأول، وقد حسب معامل الثبات باستخدام معامل ارتباط بيرسون إذ بلغ (0.83) وهي نسبة جيدة جداً. إذ يعد الاختبار جيداً

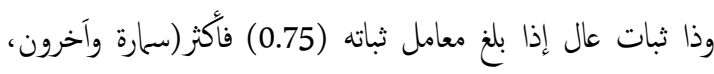
1998: 120) وبذلك أصبح الاختبار جاهزاً بصيغنه النهائية للتطبيق.
تبين الجدول (3) أن جميع القيم التائية المحسوبة اقل من القيم الثائية الجدولية والبالغة (1.96) عند مستوى دلالة (0.05) ودرجة حرية (49) وهذا يدل على أنه لايوجد فروق بين متوسطات درجات بموعتي البحث (النجريبية والضابطة) عند المتغيرات المذكورة اعلاه، وبذلك عدت بموعتي البحث متكافئتأن فيا بنهها. 4.5.3 أداة البحث تطلب البحث الحالي أعداد أداة لتحقيق هدفه والتحقيق من فرضية وهو اختبار التحصيل لمادة الجغرافية وفيما يأتي توضيح أداة: 1.4.5.3 أداة اختبار التحصيلي المعرفي لمادة الجغرافية يتطلب البحث الحالي اختبار التحصيلي المعرفي لمادة الجغرافية لمجموعتي البحث

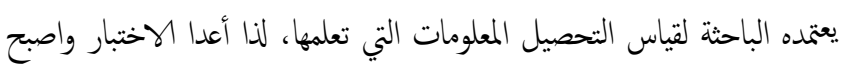
بصيغته النهائية مكون من (32) فقرة الملحق (2). أ. الخارطة الاختبارية (جدول الموصفات): هو جدول ثنائي يجمع بين الاغراض السلوكية والمحتوي ويفيد جدول الموصفات بشكل خاص في بناء اختبار متوزان ومتوائم (دوران، 1985: 29). اذا يككن أن يوفر هذا الجدول درجة مقبولة من صدق متوي الاختبار، أو صدق تمثيل عينة الفقرات للأهداف، اذ قسمت الموضوعات واوزانها والمستويات(عودة، 1998 لذا اعتمدت الباحثة جدول المواصفات الذي شمل موضوعات كناب الجغرافية المقرر تدريسه لطالبات المرحلة العاثر الادبي، والاغراض السلوكية للمستويات ضمن المجال المعرفي لتصنيف بلوم (Bloom)، (التذرك، التطبيق، التحليل، التزكي)، كما حددت اوزان المتوي الدراسي بهري في ضوء عدد الاغراض السلوكية لكل فصل من فصول الكناب، والجدول (4) يوضح عدد فقرات كل خلية في جدول المواصفات.

جدول (4) المارطة الوختبارية (جدول المواصفات) للاختبار التحصيلي المعرفي

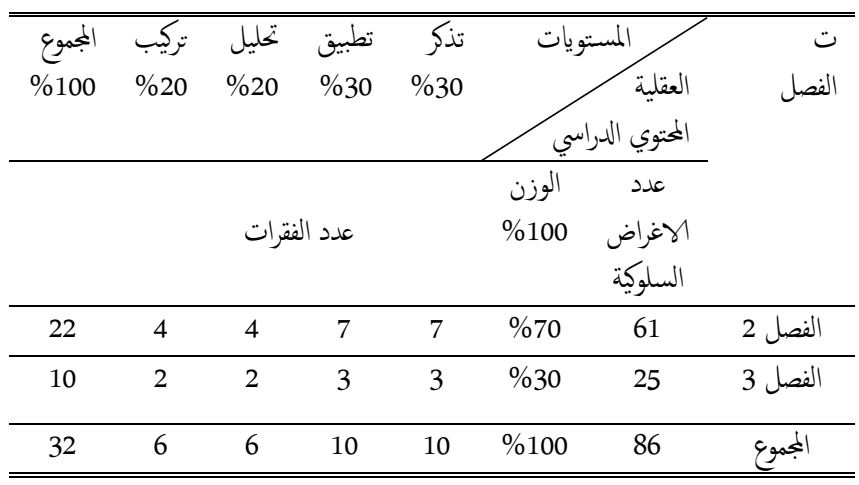




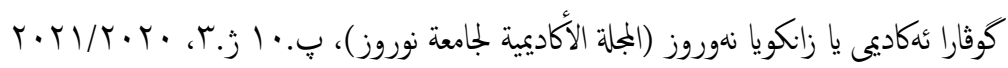

معادلة القوة التمييزية للفقرة: استخدمت للإيماد تمييز فقرات

الاختبار (النهان، 2004: 194-199).

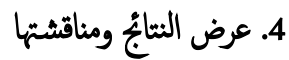

1.4

يتضمن هذا الفصل عرضاً للنتائُ والتحقق من الفرضية البحث وكالاتي:

غرض التحقق من الفرضية الصفرية التي تنص على أنه: "لا يوجد فرق ذو

دلالة احصائية عند مستوى (0.05) بين متوسط درجات تحصيل طالبات

المجموعة التجريبة اللواتي يدرسن مادة الجغرافية على وفق استراتيجية التعلم

التوليدي، ومتوسط درجات التحصيل لطالبات المجموعة الضابطة اللواتي

يدرسن مادة الجغرافية على وفق الطريقة العتيادية".

قامت الباحثة بالمقارنة بين درجات المجموعة التجريبة والمجموعة الضابطة في الاختبار التحصيل، وباستخراج المتوسط الحسابي للمجموعة التجريبية البالغ (19.84) والأخراف المعياري فبلغ (4.91)، إما بالنسبة الى المجموعة الضابطة فبلغ (16.32) والأخراف المعياري فبلغ (4.77)، وعلى الرغ من أن متوسط درجات طالبات المجموعة التجريبية كان اعلى من متوسط درجات الطالبات الجمموعة الضابطة على اختبار التحصيل لا أن الباحثة ارتأت معرفة دلالة الفرق بين متوسط درجات المجموعتين لاختبار صحة الفرضة اعلاه، وباعتماد معادلة (t-test) عند مستوى دلالة (0.05) ودرجة حرية (49) حيث بلغت القمة المحسوبة (2.59) وهي اكثر من الثيمة الجدولية (1.96)، والجدول (5) يوضح ذلك. جدول (5) المتوسط الحسايي الأنحراف المعيارية والقمة الثائية المسوبة والجدولية بين درجات الاختبار التحصيلي للمجموعتين التجريية والضابطة

\begin{tabular}{|c|c|c|c|c|c|c|c|}
\hline عند مستوي دلالة الدائة & الجدائية & الخسوبة & لدربة & المعهراف & الحسابي & العدد & الجموعة \\
\hline \multirow{2}{*}{ دالة إحصائيًا } & \multirow{2}{*}{1.96} & \multirow{2}{*}{2.59} & \multirow{2}{*}{49} & 4.91 & 19.84 & 26 & التجربيية \\
\hline & & & & 4.77 & 16.32 & 25 & الضابطة \\
\hline
\end{tabular}

وهذا يدل على أن الفرق بين متوسطي الفروق ذو دلالة إحصائية لصاخ المجموعة التجريية التي درست استراتيجية التعلم التوليدي، وبذلك ترفض الفرصية الصفرية.
د. تطبيق التجربة: بعد أن كافأت الباحثة بين مجموعتي البحث (النجريبية والضابطة) في عدد من المتغيرات فضلاً عن تهيئة الأداء وتنظيم جدول الحصص الاسبوعي ومجموعة الخطط التدريسية على وفق استراتيجية التعلم التوليدي والطريقة الاعتيادية، وراعيا السلامتين الداخلية والخارجية في عدد المتغيرات بدأت تطبيق التجربة بشكل فعلي وعلى النحو الاتي: بدأ تنفيذ اجراءات البحث في يوم السبت الموافق (2019/10/5) اذ تم تدريس المجموعة التجريبية على وفق استراتيجية التعلم التوليدي، وتم تدريس المجموعة الضابطة على وفق الطريقة الاعتيادية، واستمر لغاية يوم الاثثين الموافق (2019/12/2) أي استغرق تطبيق التجربة (9) أسبوعاً تقريباً وبواقع (3) درس أسبوعياً ليكون المجموع الكلي للدروس (27) درساً

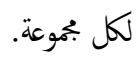

هـ تطبيق أداة البحث: بعد أنتهاء التجربة طبق الباحثة الأداة اختبار التحصيل لملادة الجغرافية في يوم الأحد الموافق (2019/12/1) على أفراد عينة البحث، بعد أن تم إخبارهن بموعد الاختبار قبل عدة أيام لغرض التحضير لألاء الاختبار. و. تصحيح أداة البحث: تم تصحيح أداة البحث (اختبار التحصيل) كلألتي: بما أن الاختبار هو اختبار موضوعي، فقد وضع منتاحاً لتصحيح فقرات الاختبار وحدد بموجبه درجة(1) للإجابة الصحيحة و(0) للإجابة الخاطئة أو المتروكة أو المؤشر بأكثر من بديل، وبذلك ترواحت درجة اختبار التحصيل من (0- 32) درجة. ز. الوسائل الإحصائية. استخدم الباحثة الوسائل الإحصائية الآتية: الاختبار التائي لعينتين مستقلنين لأغراض التكفؤ وتحليل نتائج

$$
\text { البحث (البلداوي، 2004: 227). }
$$

معادلة ارتباط بيرسون: لحساب معاملات الثبات لأداة البحث(عدس

$$
\text { وعبداله، 2008: 181) (181). }
$$

الاختبار التائي (t-test) لعينتين متربطين: أستعمل لتحليل نتائج

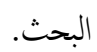

معامل الصعوبة: استخدمت لحساب معامل صعوبة فقرات الاختبار التحصيلي. 


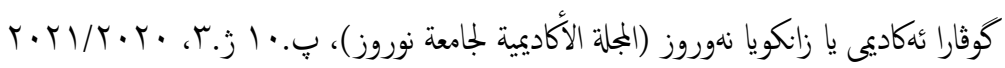

ساهمة استراتيجية التعلم التوليدي بصورة ايجابية في زيادة التحصيل المعرفي

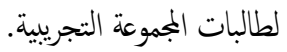

استخدام استراتيجية التعلم التوليدي كان اكثر تأثيراً في مستوي التحصيل المعرفي من الطريقة التقليدية ما يدل على فاعليته وتأثيره.

$$
\text { رابعأ-التوصيات: }
$$

في ضوء النتانُج التي توصل اليها هذا البحث توصي الباحثة بما يأتي: أن يعتمد مدرسي ومدرسات الادبي استراتيجية التعليم التوليدي في تدريس الاجتاعيات العامة (الجغرافية) لما له من أثر ايجابي في التحصيل. ادراج استراتيجية التعليم التوليدي في الادبي وكليات التربية ضمن مقرر طرائق تدريس الجغرافية. أن تعمل وزارة التزبية في أقليم كوردستان/العراق ومديرياتها تدريب مدرسي ومدرسات الجغرافية بصفة خاصة والإجتاعية بصفة عامة على كيفية استخدام استراتيجية التعليمة الحديثة ولا سيا استراتيجية التعليم التوليدي

$$
\text { من خلال عقد الدورات والندوات التربوية. }
$$

أن تعمل وزارة التربية في أقليم كوردستان/العراق ومديرياتها توجيه أنظار القائمين على تاليف كتب طرائق التدريس الجغرافية بشكل تفصيلي عن استراتيجية التعليم التوليدي وذلك بسبب قلة المصادر التي تحدثت عن هذه استراتيجية علماً أنه من الناذج التي تعمل بها حديثاً في عالم، اضافة الى قلة

$$
\text { الدراسات التي تناولتها. }
$$

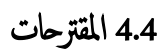

استكمالاً للبحث الحالي تقترح الباحثة ما يلي: 1.الاعتاد على الاختبار المعرفي في تقو.يم التحصيل المعرفي لطلبة الصف

$$
\text { العاشر الادبي في مادة الجغرافية. }
$$

2.تضمين استراتيجية التعلم التوليدي ضمن مفردات مادة طرائق الندريس في كليات واقسام التربية بصورة عامة وقسم الجغرافية بصورة خاصة لكي يلم هها الطلبة في اثناء اعدادهم لمهنة التدريس.

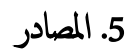
1. أبو جادو، صالح محمد علي (2013) علم النفس التربوي، الطبعة الثانية، دار المسيرة للطباعة والنشر والتوزيع، عان، الأردن.

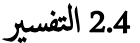

تبين النتائُ التي تم الحصول عليها أن لاستخدام التعليم التوليدي الأثر الايجابي في زيادة التحصيل لدي طالبات العاثر الادي، ويعود ذلك للأسباب الأتية: أن التدريس على وفق هذا استراتيجية يتيح للطالبات الفرصة لبناء معارفهن من خلال الثفاعل الايجابي مع مدرسة المادة، فضلاً عن الثفاعل بين الطالبات أنسهن، والتوصل فيا بنين وذلك باستخدام اللغة والحوار واستخدام التعبيرات وتبادل الأراء مما قد يثير اهتمام الطالبات والهوض بمستواهن العلمي لأقصى ماتسمح به قدراتهن وامكانياتهن وقابلياتهن. أن التعلم ضمن مجموعات صغيرة يمنح الطالبات الثقة بالنغس والتعاون فيا بينهن من اجل اكتشاف الاجابة الصحيحة والنبادل بالمعلومات بين الطالبات حيث يتيح الندريس بهذا اسراتيجية توظيف التعلم التعاوني واللغة والحوار.

أن استراتيجية التعليم التوليدي يدفع الطالبات للتفكير وذلك لأنه تطبيق لنظرية المعرفة وهذه النظرية تؤكد على مفهوم تنمية المنطقة المركزية وذلك مما

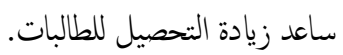
امكن ملاحظة الثفاعل الذي ساد الموافق التعليمة اذ أسهم استراتيجية التعليم التوليدي في مساعدة الطالبات على المشاركة الإيهابية ما عزز الثقة بالنفس والقدرة على الاستنتاج، كما أصبحت لديهن القدرة على استخدام المفورم في مواقف تعلمية جديدة من خلال تحديد وظيفية أو فائدة

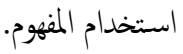
أن استخدام هذا استراتيجية في التدريس بخلاف الطرائق والأساليب الثقليدية التي يتبعها المدرسون في الصف، حيث أن استخدام هذا استراتيجية في التدريس يؤدي المى تغزيز المفهوم وتطبيقه في مواقق تعليمية

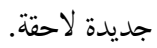

$$
\text { في ضوء نتائُ هذا البحث يمكن للباحثة أن تستنج الأتي: }
$$
ساهمة الطريقة التقليدية بصورة ايهابية في زيادة التحصيل المعرفي لطالبات

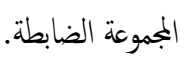




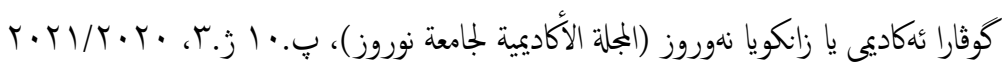

20. عبد السلام، مصطني (2006) تدريس العلوم ومتطلبات العصر، الطبعة الأولى، دار الفكر العربي للنشر والتوزيع، القاهرة، مصر.

21. عدس، عبد الرمن وعبد الله المنيزل (2008) مقدمة في الإحصاء التزبوي، الطبعة الثانية، دار الفكر ناشرون وموزعون، عان، الأردن.

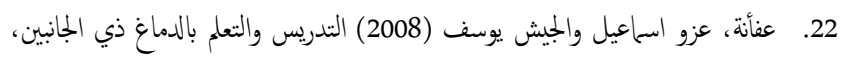
مكتبة افاق للنشر والتوزيع، غزة، فلسطين. 23. عودة، احمد سليان (1998) القياس والتقويم في العملية التدريسية، دار الأمل للنشر والتوزيع، عان، الأردن.

24. الكبيسي، عبد الواحد مميد (2012) الأر استراتيجيتي التعلم التوليدي والتساؤل الذاتي

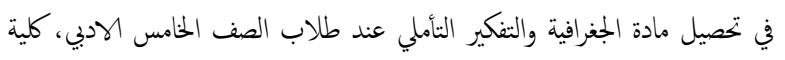
الزبية ابن رشد-جامعة بغداد، (اطروحة دكتوراه غير منشورة).

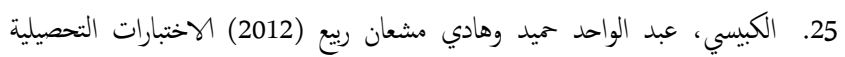
المدرسية، الطبعة الأولى، مكتب الجمتع العربي للنشر والتوزيع، عمان، الأردن.

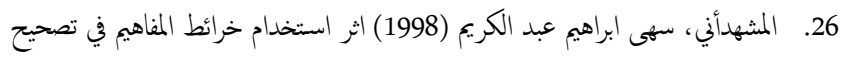
الاخطاء الشائعة لدى طالبات الصف الثأين متوسط في المفاهيم الكميائية، كلية التربية

$$
\text { ابن الهيثم- جامعة بغداد، (اطروحة دكتوراه غير منشورة). }
$$
27. النهان، موسى (2004) أساسيات القياس في العلوم السلوكمة، الطبعة الأولى، دار الشروق اللنشر والتوزيع، عمان، الأردن.

28. النجدي، أممد وآخرون (2005) اتجاهات حديثة لتعليم العلوم في ضوء المعايير العالمية وتنمية التفكير في ظل النظرية البنائبة، دار الفكر العربي للنشر التوزيع، القاهرة، مصر.

29. Whith,R.T.\& Gunstone, R.F.(1989) Metal learning and conceptual change, International Journal of science Education, Vol: 11,NO: 6, PP: 86-577.

30. Bloom, B.S. et.al (1971) Handbook on Formative and Summative Evaluation of Student Learning, New York, McGraw-Hill.

31. Wittrock, M.C. (1991) Generative teaching of comprehension, Elementary school Journal, Vol: 8, No: 92, PP 82-167.
2. أحمد، فاطمة (2013) استخدام نموذج التعلم التوليدي في تنمية بعض عمليات العلم

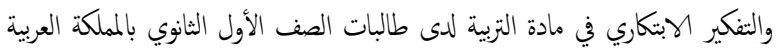

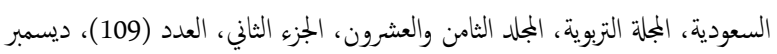

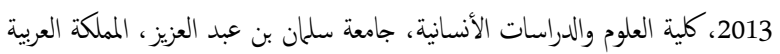
السعودية. أحمد، محمد بخيت السيد (2009) أثر استخدام نموذج التعلم التوليدي في تدريس

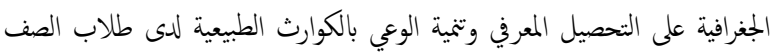
الأول الثانوي، كلية التربية- جامعة سوهاج، (رسالة ماجستير غير منشورة).

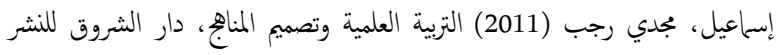
والتوزيع، عمان، الأردن. 5. البلداوي، عبد المميد عبد المجيد (2004) أساليب البحث العلمي والتحليل الإحصائي، الطبعة الأولى، دار الشروق للنشر والتوزيع، عان، الأردن.

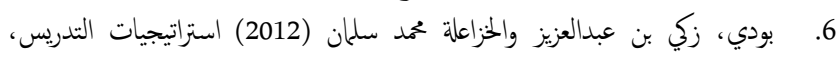
الطبعة الأولى، دار الخوارزي للنشر والتوزيع، المملكة العربية السعودية.

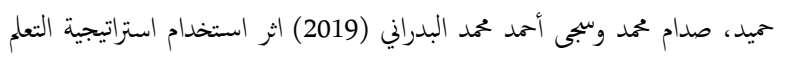

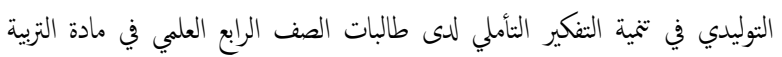
الاسلامية، المؤتمر العلمي الدولي الاول، جامعة دهوك، العراق.

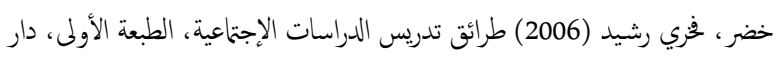
المسيرة للنشر والتوزيع والطباعة، عمان ، الأردن.

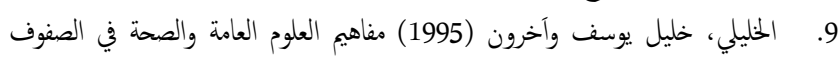
الاربعة الأولى، مطابع الكناب المدرسي للنشر والتوزيع، صنعاء، اليمن.

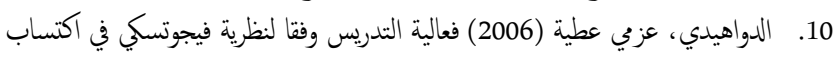

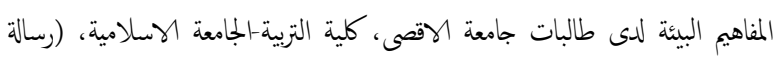

$$
\text { ماجستير غير منشورة) }
$$

1. دوران، رودني (1985) اساسيات القياس والتقويم في تدريس، ترجمة: محمد سعيد صباريني وآخرون، دار الأمل، إربد.

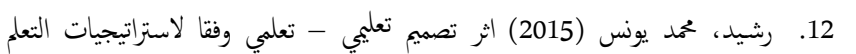

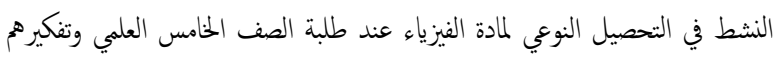
السابر، كلية التربية ابن الهيثم-جامعة بغداد، (اطروحة دكتوراه غير منشورة).

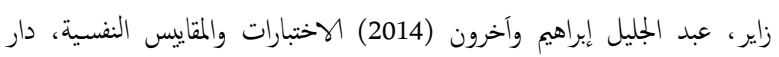

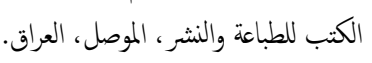

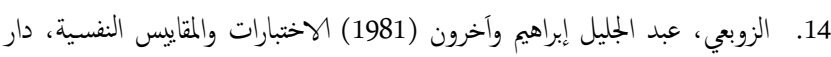
الكتب للطباعة والنشر، جامعة الموصل.

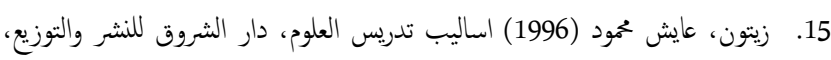
عان، الأردن. 16. سارة، عزيز وآخرون (1989) مبادئ القياس والتقويم في التربية، دار الفكر للنشر والتوزيع، عمان، الأردن.

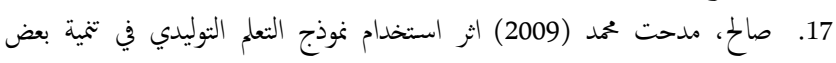

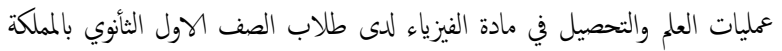
العربية السعودية، المؤتمر العلمي الحادي والعشرون، جامعة عين شمس التهر، القاهرة.

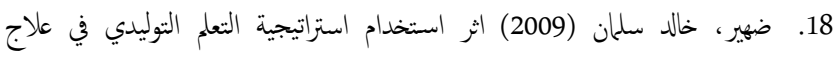

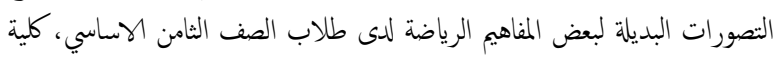
التربية-الجامعة الاسلامية، غزة، (رسالة ماجستير غير منشورة).

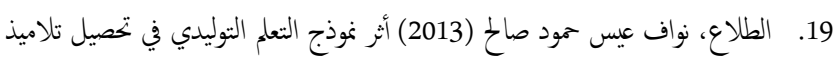
الصف الخامس الابتدائي في مادة التاريخ وتنمية المهارات الإجتماعية لدهيه، كلية التزبية الاساسية-جامهة موصل، (رسالة ماجستير غير منشورة).

\section{3}

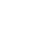
4 5

6
.7 .8 .

0

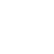

$$
11
$$




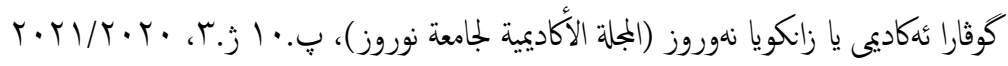

الملحق (1)

\section{أسهاء السادة المهكين اللين استعانت الباحثة بخبراتهم في بعض إجراءات البحث}

\begin{tabular}{|c|c|c|c|c|c|c|c|}
\hline \multicolumn{3}{|c|}{ طبيعة الاستشارة 2*2 } & \multirow{2}{*}{ مكان العمل } & \multirow{2}{*}{ الاختصاص } & \multirow{2}{*}{ اللقب العلمي } & \multirow{2}{*}{ 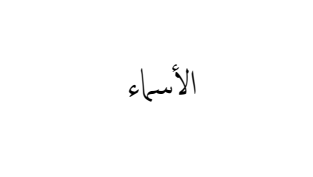 } & \multirow{2}{*}{ ت } \\
\hline 3 & 2 & 1 & & & & & \\
\hline * & * & * & جامعة دهوك -كلية التزبية الأساسية & طرائق تدريس التاريخ & أستاذ & د.إسهاعيل أحمد سمو & 1 \\
\hline * & & * & جامعة دهوك -كلية التربية الأساسية & القياس والتقويم & أستاذ & د.صابر عبدالله سعيد & 2 \\
\hline & & & جامعة الموصل-كلية التربية & طرائق تدريس الفيزياء & 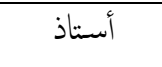 & د. عبدالرزاق ياسين عبدالله & 3 \\
\hline & & & جامعة صلاح الدين-كلية التربية & طرائق التدريس العام & أستاذ & د.حسين سعدي إبراهيم & 4 \\
\hline & * & & جامعة دهوك-كلية الأداب & جغرافية بشرية / مدن & أستاذ مساعد & د.نشوان شكري عبدالله & 5 \\
\hline * & * & * & جامعة دهوك -كلية التربية الأساسية & جغرافية بشرية/ مدن & أستاذ مساعد & د. نيشان سورين & 6 \\
\hline * & * & * & جامعة دهوك -كلية التربية الأساسية & طرائق تدريس & 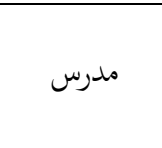 & ج. جيمن حكيم موسى & 7 \\
\hline & * & * & مدرسة ئامةد -دهوك & مادة جغرافيا & 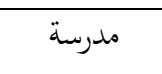 & سبير معروف طه & 8 \\
\hline & * & * & مدرسة هةسار دهوك & مادة جغرافيا & مدرسة & افين ججي محد & 9 \\
\hline
\end{tabular}

2 طبيعة الاستشارة: 1.الأغراض السلوكية، 2. الخطط الندريسية، 3. الاختبار التحصيلي. 


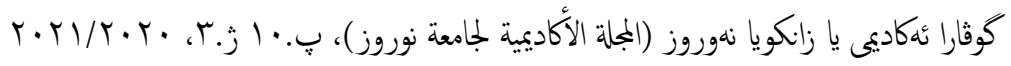

الملحق (2)

فقرات الاختبار التحصيلي المعرفي بصورته النهائية تعليات الاختبار

عزيزتي الطالبة ....

الاختبار الذي بين يديك مكون من (32) شؤالا، لكل سؤال اربع إجابات واحد منها صحيحة، ضع دائر حول الحرف الذي تدل على الاجابة التي تزاها صحيحة، وكما في المثال ادناه:

- - الزمن الخمص للاختبار هو (40) دقيقة.

مثال:

الكوارتز من الصخور المتحولة أصلة:

ج- أر الرملية

مع تمنياتي لكم بالنجاح

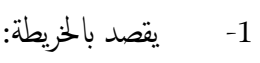

أ. ارض مستوية أو شبه مستوية تعتمد على مساحة كيرة.

ب.التعبير عن المعالم والظواهر الطبيعية والبشرية المختلفة على سطح الارض.

ج.ججرد ماء عذب منحدر الى بهيزة أو بحر.

د.ارض متعرجة تمتد الى مسافة قليلة. 


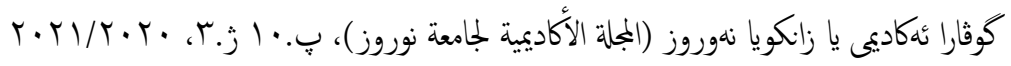

2- يككن تشخيص فوى أية خريطة من خلال:

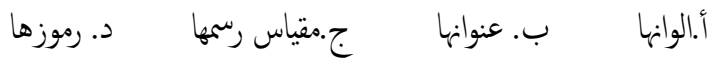

3- يعرف مقياس الرسم بانه النسبة بين بعدين احدها على:

أ.اليابسة والثاني على الماء ب. خريطة والثاني على الجو

ج. الطبيعة والثاني على الماء د. الطبيعة والثاني على الخزيطة

4- أي من الاتي ليس من أنواع مقياس الرسم:

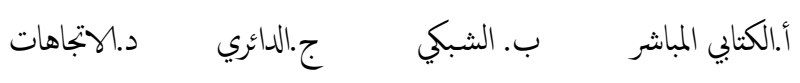

5-المقياس الخطي عبارة عن خط مستقيم وموقعه من الخزيطة في:

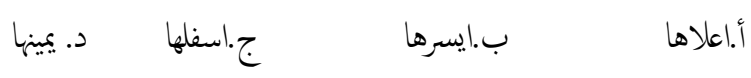

6- 6 - 6تجه ظل العصا عند الزوال نخو الشمال في الساعة:

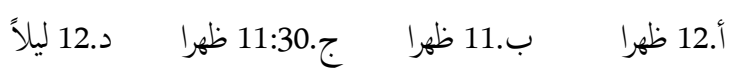

7-تتمثل أهمية مفتاح الخريطة في كونها يحدد من خلاله:

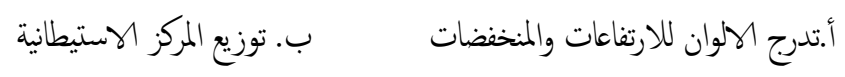

ج.توزيع الظواهر المتعلقة بالتزكيب البيئى ـ.الطرق التخطيطية لنكبير الخريطة

8- اللون الذي يرمز به الى الحدود الدولية والادارية هو:

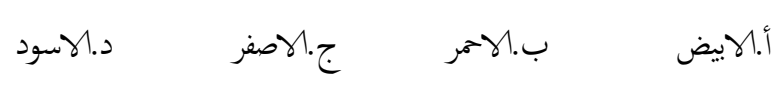

9-تمثل طرق السيارات غير المعبدة على الخريطة برمز خطوط:

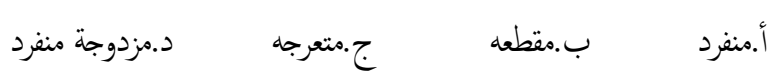

10-يستخدم اللون الاخضر في الخريطة للدلالة على ظاهرة جغرافية:

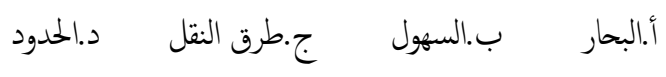

11-تمثل خطوط السكك الحديد على الخريطة بشكل خطوط: 


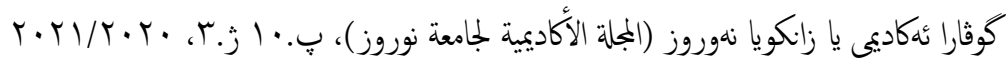
أ.الممراء ب.سوداء ج.مزدوجة حمراء د.مزدوجة سوداء

12- اللون الذي يستخدم لتمثيل البحار العميقة هو:

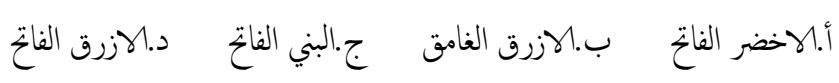

13-تسمى الخزئط التي تهتم بتوزيع الظواهر الطبيعية والبشرية القديمة بخرائط:

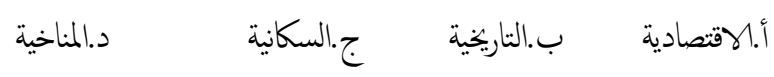

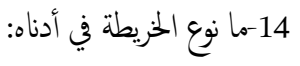

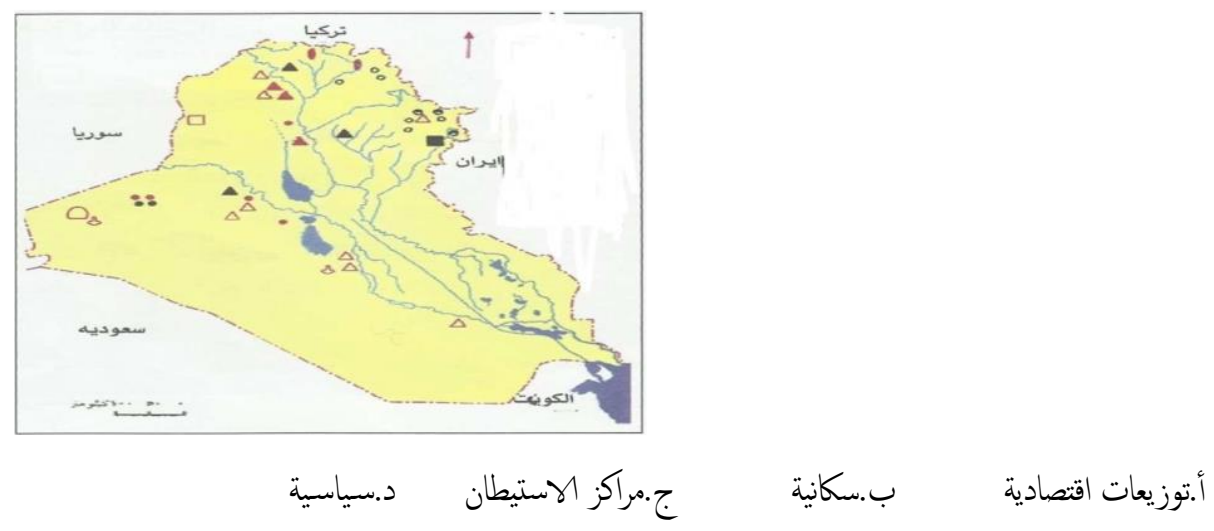

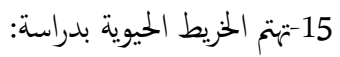

ب.عناصر المناخ من حيث درجات الحرارة

أ.اشكال سطح الارض

ج.انواع النباتات والحيوانات على سطح الارض د.البحار والميطات ومافيها

16-الطريقة المستخدمة عند تكبير وتصغير المناطق الضيقة هي:

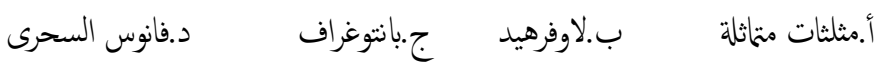

17-يعود نجاح معمل الادوية في سامراء المى:

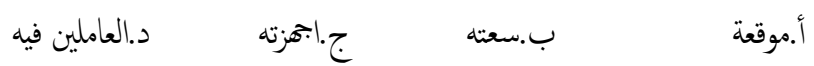

18-الرخام هو احد أنواع الصخور: - الص

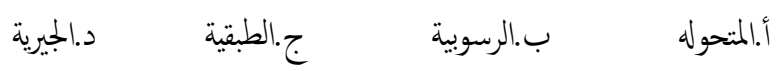




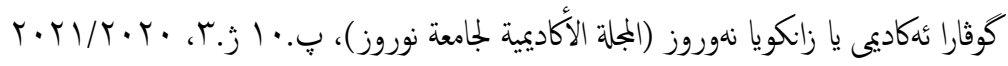
19-النايس من الصخور المتحولة أصله:

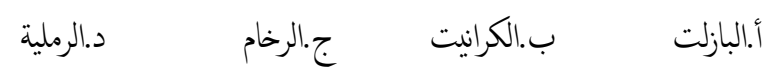

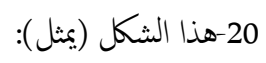

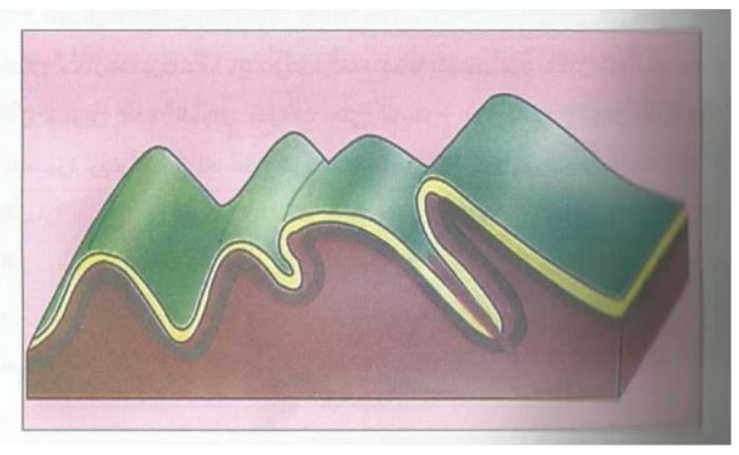

أ.هضاب التوائية ب.الجبال الاتوائية ج.التضاريس د.الحركة الالتوائية للقشرة الارضية

21-يقصد بصطلح التضاريس الأرضية الدلالة على:

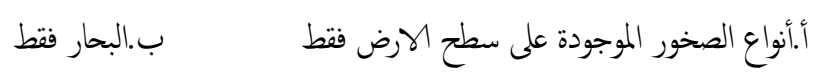

ج.الظواهر المتنوعة لسطح اليابسة من مرتفعات ومنخفضات د.المعالم والظواهر المختلفة على سطح الرض برض

22-تعرض بعض أجزاء القشرة الارضية للدفع من جانب واحد او من جانيين يؤدي الى تكوين الجبال:

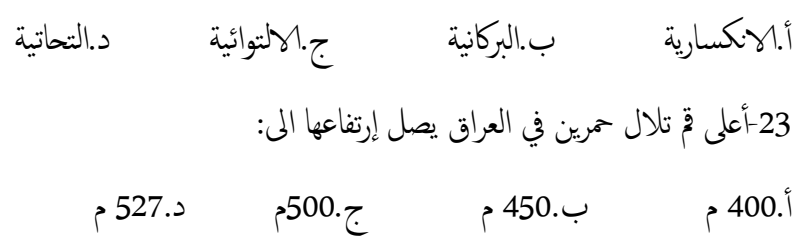

24-الأرضى المرتغعة ذات السطوح المستوية قلية الوعوزة، تسىى:

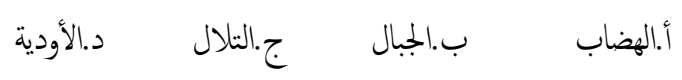

25-تتكون الاوديه التكتونية بفعل:

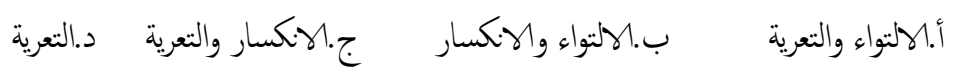

26-تسمى الأراضى المنبسطة الفسيحة التي لا ترتغع كثرا عن مستوى سطح البحر ب:

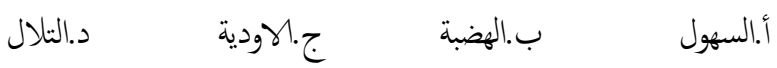




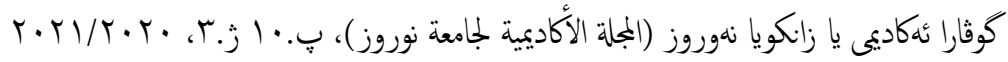
27-السهول الفيضية هي أفضل أنواع السهول:

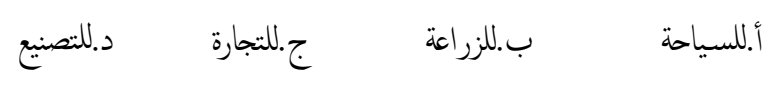
28-يلجأ الكثيرون الى الاستيطان بالأراضي السهلة وذلك: أ.لخصوبتها ب.سهولة الحركة والعمل ج.لاعندال مناخها د.لكثرة امطارها 29-29-من عوامل التي تساعد على تكوين الدلتا:

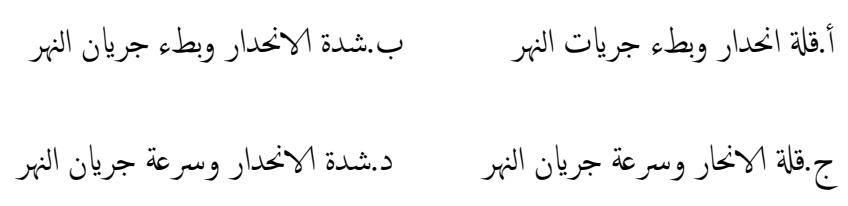

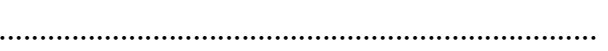
30-لاحظ الاشكال الاتية وأختر حرفاً لمفوم الدلنا النهرية:
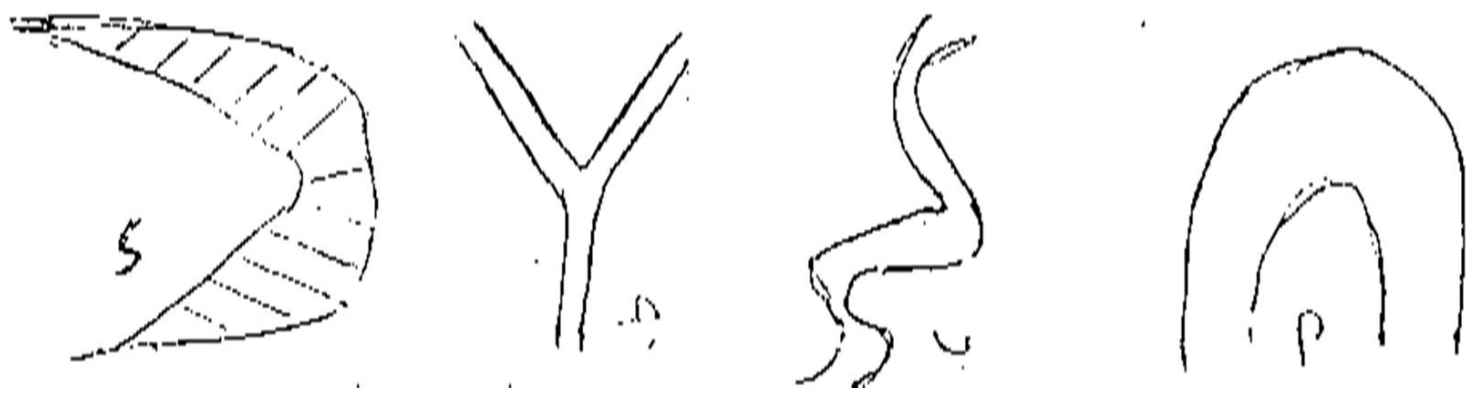

31. .ان ارتفاع الغلاف الغازي هو :أ..(4000)§

32.عندما نجمع متوسط احر الشهور و متوسط أبردها و نتسم الحاصل على اثنين نحصل على المتوسط :-

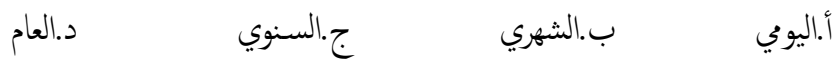

